\title{
Barbara Chester Award 2019
}

\author{
Mary Fabri, PsyD *
}

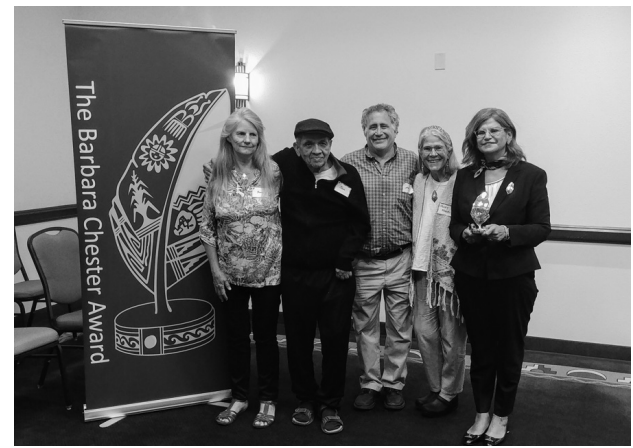

From Left to Right:

Shari Eppel from Zimbabwe 2000 BCA recipient Juan Almendarez from Honduras 2001 BCA reipient Allen Keller from the United States 2003 BCA recipient Mary Fabri from the United States 2009 BCA recipient Sana Hamzeh from Lebanon 2019 BCA recipient

The Hopi Foundation, a non-profit organization in Kykotsmovi Village, Arizona, honors the life and work of Dr. Barbara Chester, torture rehabilitation pioneer, with an award for outstanding practitioners who assist torture survivors, their families, and communities. The 2019 Barbara Chester awardee was Dr. Sana Hamzeh, Clinical Advisor of the Restart Center for Rehabilitation of Victims of Violence and Torture in Lebanon. The event took place on October $5^{\text {th }} 2019$ in Moenkopi, Arizona.

^) Mental Health Consultant and Trainer. 2009 Barbara Chester Award recipient

Correspondence to: mrfabri@hotmail.com
The morning workshops shared experiences of healing through the use of cultural traditions, pilgrimages, and exhumations as a tool for transformation. The afternoon award program included keynote remarks by Dianna Ortiz, a survivor and co-founder of Torture Abolition and Survivor Support Coalition. She described the event, "This weekend has given me the courage to dare to believe the impossible: looking beyond pain and distress may lead to the uncovering of a calm, healthy and an unblemished soul surrounded by hope and tranquility. Perhaps healing from torture is, indeed, possible."

Dr. Hamzeh, nominated by her friend and colleague, Suzanne Jabbour, spoke eloquently about the moral obligation providers come to feel, "I am here to give the hundreds of torture survivors I have worked with throughout the years, a voice. I am giving my voice to their pain, needs, fears, hopes, strength, resilience and survival stories." She also voiced the feeling that Barbara Chester Awardees share when they learn of their receiving the award, "a realization that our hard work and efforts can, and will be, recognized" that then renews our hopes and motivations.

The Barbara Chester Award is given every three years and nominations are solicited from around the world. Past awardees are: Shari Eppel of Zimbabwe (2000); Juan Almendarez of Honduras 
(2001); Allen Keller of the United States (2003); Alp Ayan of Turkey (2006); Mary Fabri of the United States (2009); Naasson Munyandamutsa of Rwanda (2013); and Diana Kordon of Argentina (2016). Sana Hamzeh of Lebanon (2019) is welcomed to the family of Barbara Chester Awardees.

The next request for nominations will be in October of 2021 for the October 2022 award that includes a cash prize of $\$ 10,000$ USD and a silver sculpture featuring Hopi symbolism for healing and Qa Tutsawinvu - freedom from fear of intimidation from any source. Noted Hopi artisan, Floyd Lomakuyvaya, handcrafts the award.

Please be ready to nominate a dedicated and tenacious practitioner for the 2022 Barbara Chester Award. http:// barbarachesteraward.hopifoundation. org/home 